\title{
Mario Vargas Llosa: angustia, rebelión y compromiso en la nueva Literatura Peruana
}

Por ROSA BALDORI

¿Quién es este joven escritor peruano varias veces premiado, cuyas ficciones narrativas han sido tan comentadas y alabadas por la crítica, y se han traducido (o están en vías de traducción) en Alemania, EEciUUl,i, Francia, Finlandia, Bulgaria, Checoslovaquia, Inglaterra, Rusia, Israel, Italia, Suecia, etc.? Presentaré en primer término al hombre Mario Vargas Llosa, a través de breve noticia biográfica, para destacar luego en qué forma toda su problemática literaria se inscribe dentro del vasto y rico campo de la literatura hispanoamericana de hoy, y en especial de la actual literatura peruana ( $\tan$ poco conocida aquí, por ese ridículo aislamiento cultural que aún persiste entre las naciones iberoamericanas). Enfocaré luego el conjunto de su obra, para detenerme finalmente en la consideración de sus dos grandes novelas: La ciudad y los perros, y La casa verde.

Nacido en 1936 en la segunda ciudad del Perú, Arequipa, M. Vargas Llosa cursó sus primeros estudios en Cochabamba (Bolivia), y los secundarios en Piura y Lima, donde asistió por algún tiempo al Colegio Militar Leoncio Prado, experiencia de

* La autora es argentina. 
choque brutal con una realidad nueva, que habria de revertir en forma tan vívida y descarnada en su primera novela, $L a$ ciudad y los perros. Se licenció en Letras en la vieja Universidad de San Marcos de Lima y en 1958 obtuvo una beca para hacer el doctorado en Madrid. Desde entonces hasta hoy reside en Europa. Al año de su estadía en Madrid, y después de haberse doctorado, se trasladó a París, donde pasó algunos meses difíciles. Al principio daba lecciones en la escuela Berlitz; más adelante entró a trabajar en la France Press, en la sección española, y finalmente en la Radio Diffusion Francaise, donde tiene ahora trabajo permanente, que alterna con el periodismo y una activa dedicación a la creación literaria. Junto con otros escritores latinoamericanos (entre ellos Julio Cortázar, Carlos Fuentes, Elvira Orfée, Héctor Bianchotti, Damián Carlos Bayón), participa de ese grupo de artistas (escritores, pintores, escultores, elencos teatrales), cuya presencia creadora hace que en estos momentos, el panorama cultural francés que se resume en París, sea compartido por América Latina en igualdad de condiciones. "Una recorrida por las galerias de arte, los teatros, las librerías de la capital francesa, nos revela de inmediato este hecho que, dos décadas atrás, nos hubiera parecido el sueño de algún olvidado artista latinoamericano", afirma la Carta de París de Julián Cairol, aparecida en el número de junio de este año en "Mirador", órgano de la Fundación Interamericana para las Artes, que más adelante agrega: "En el prólogo de "Les mots et les choses" de Michael Foucault, libro de reciente aparición y considerado como la obra filosófica de mayor importancia desde LEtre et le Néant de Jean Paul Sartre, oebautorcireconoce larimportancia que un cuento de Borges tuvo en la eląboración de su teoría. Este hecho resulta significativo para tener una idea de la importancia que los autores franceses contemporáneos le asignan a la literatura latinoamericana, de no muy lejana irrupción en los círculos literarios europeos. Si bien es cierto quẹ Borges debe ser considerado como un pionero, es oportuno señalar aquí que este hecho viene a revelar no sólo el grado de madurez alcanzado por la literatura latinoamericana, sino la subversión de roles, esto es de literaturas influidas a literaturas influyentes. Y si esto, dicho así, pudiera aparecer como un juicio prematuro, debemos admitir que al menos es un índice de la independencia adquirida por la literatura de los paises latinoamericanos". Concluye el artículo con las palabras de Arrabal, quien -dice Cairol- al semos presentado, dijo: - Latinoamericanos, ¿es que habéis sido llamados para salvar a Francia?

En efecto, para tener una idea del vigoroso empuje de la prosa latinoamericana de los últimos 10 ó 15 años, nos bastará 
arrojar una mirada de conjunto sobre sus obras, para sorprendernos ante el número de nombres valiosos que encontramos: Mario Vargas Llosa, Mario Benedetti, Carlos Fuentes, Vicente Leñero, Juan Rulfo, Julio Cortázar, Ernesto Sábato, Ricardo Donoso, Carlos Heyremans, Alejo Carpentier, Miguel Angel Asturias, Juan Carlos Onetti, para citar solamente algunos de sus más afamados representantes. Esta fecunda generación, rica en temperamentos fuertemente individuales, presenta también algunos rasgos comunes. Así, por ejemplo, la intención que tienen sus representantes de dar, a través de la ficción narrativa, una visión realista, totalizadora y crítica de sus países de origen, haciendo hincapié en la estructura y génesis de los fenómenos sociales, políticos y económicos concomitantes con la extraordinaria explosición demográfica producida en el siglo XX en las grandes capitales: México, Montevideo, Buenos Aires, Lima, Santiago. La tónica fundamental la da el sentimiento de angustia, la rebelión contenida y desesperanzada contra la injusticia social, la incomunicación, de los habitantes de las grandes urbes americanas. Para expresar to da esta problemática con la mayor gama de tonalidades posible, presentando además de la realidad aparencial y consciente el símbolo, la realidad profunda, inconsciente, mágica, mítica, los sueños, estos escritores buscan incesantemente nuevas formas de lenguaje, y así resultan activos transformadores de las estructuras de la prosa castellana.

Una visión de la última producción literaria del Perú, nos revelará asimismo cómo la obra de Vargas Llosa no constituye allí tampoco ún fenómeno aislado, cómo" se inscribe dentro de un proceso envolvente y general. Recordemos que el Perú ofrece, entre sus múltiples rostros, dos muy distintos: el de la costa (digamos mejor, Lima), y el del interior (la sierra, la selva); que tradicionalmente la literatura había acostumbrado a los lectores a buscar en los libros esta $2 \mathrm{a}$. faz peruana. $\mathrm{Pe}$ ro ¿qué pasa con el público actual? Leamos las interesantes manifestaciones de $M$. Vargas Llosa, vertidas en la mesa re. donda realizada en La Habana, el año pasado, sobre $L a$ ciudad $y$ los perros: "Los lectores latinoamericanos han sido, y son hoy en día, lectores de ciudades, y la novela latinoamericana es una novela que ha registrado, ha representado verbalmente realidades que a esos lectores les resultaban inéditas, ignoradas"... "una novela como "El mundo es ancho y ajeno", de Ciro Alegría, leída por lectores limeños, por lectores de la costa, resultaba casi tan exótica como las novelas de autores franceses sobre París, o de autores ingleses sobre Londres. Entonces, la concepción involuntaria, no muy consciente, que sobre 
la literatura se podía formar uno de esos lectores era, yo diría, exotista".. "Cạsi no existe una novela urbana, casi no existe una novela del hombre de la costa, ni del hombre de Lima. Ver reflejada en un libro esta realidad que uno conoce, que es propia, significa siempre tomar conciencia de ella... Y esto es siempre un escándalo... Yo estoy convencido de que la literatura es intrínsecamente escandalosa. Permite al hombre tomar conciencia de su realidad, de esa faz oculta en la que él está sumido de una manera casi protoplasmática, casi ciega".

Por otra parte, cuando los autores presentaban a Lima en sus obras, nos daban de ella una imagen irreal, parcializada o idealizada, generalmente bajo el manto del esplendor virrei. nal, de sus misteriosas tapadas o de sus balcones salientes y floridos. Así también la Lima de los narradores de comienzos de siglo, fue el centro poblado próspero y frivolo, el refinado lugar de veraneo, los balnearios, el ambiente aristocrático y decadente de la ciudad misma, como acertadamente señala Estuardo Núñez (en su ponencia del 29-8-63, al Congreso de Literatura Iberoamericana, en la Universidad de Texas, publicada recientemente). Veamos algunos títulos: Cartas de una turista (de Enrique Carrillo, 1905); El hermano mayor (de Manuel A. Bedoya, 1908); Bajo las lilas (Manuel Beingolea, 1923); Sussy (José Diez Canseco, 1929), etc. ¡Qué distintos de algunos títulos recientes: Lima, la horrible (S. Salazar Bondy, 1964); Lima en rock (O. Reynoso, 1961); Lima, hora cero (E. Congrains Martín, 1954); La ciudad y los perros (MVLL, 1963), etc.

En los autores últimos aparece por primera vez la novela de la urbe, esto es, del contorno sórdido de la gran ciudad, donde se ven no ya los balcones floridos, sino las viviendas provisionales y miserables; no ya las románticas y misteriosas "tapadas", sino las muchachas hambrientas y desgreñadas que defecan (Domingo en la jaula de estera, cuento de E. Congrains Martín), que hurgan los basurales, disputando carronas con los gallinazos. Este grupo de escritores jóvenes, izquierdistas, viene dando a publicación, desde 1954, aproximadamente, una serie de obras que configuran un importante movimiento literio, rotulado como el "neo-realismo urbano" por Mario Castro Arenas (en su obra La novela peruana y la evolución so. cial) y como el "neo-objetivismo", o "novela de la urbe", por Estuardo Núñez (en su obra cit.). Las figuras más destacadas del grupo (que cuenta con una veintena de representantes) son: Mario Vargas Llosa (30 años), Enrique Congrains Martín (34), Oswaldo Reynoso (34), Julio Ramón Ribeyro (37), Car- 
los Zavaleta (39), entre otros. Algunos de los títulos más importantes: La ciudad y los perros, En octubre no hay milagros, Los geniecillos dominicales; Lima, hora cero. En todas aparece como marco, y quizás asumiendo el rol protagónico, la gran urbe del Pacífico, con su peculiar mezcla de pasado y presente (grandes y modernos edificios junto a huacas, coloniales balcones salientes, museos), sus dos millones y medio de habitantes, sus cinturas de espeluznantes villa-miserias y toda la problemática creada por el éxodo hacia la costa, el crecimiento vertical y horizontal, el lento y trabajoso surgimiento de la clase media (a que estos escritores, en general, pertenecen), el apogeo de algunas clases y el estancamiento sin salidas o la decadencia de otras.

Por primera vez, entonces, la literatura peruana muestra al mundo el verdadero torso de Lima, en toda su desnudez; literatura que no quiere autoengaños; que quiere tocar fondo, para poder elevarse desde allí algún día; literatura como vía del autoconocimiento, como toma de conciencia de la propia realidad. Acerca de estos escritores dice M. Castro Arenas, en el libro citado ( $p .259)$ : "Desplazando a la problemática rural enmohecida por la standardización de tipos y modos de expresión, la problemática urbana arribó a la novela coincidiendo con la asimilación local de nuevas técnicas narrativas. El drama del serrano inmigrante, su modus vivendi en un mundo oscilante entre la gran ciudad donde trabaja y la humilde choza de esteras donde mora, su promiscuidad forzada, inevitable, con una comparsa de extraños traficantes, delicuentes, locos, charlatanes yolsos agitadores sociales, determina una vasta perspectiva narrativa abierta a la emoción de los nuevos novelistas. Es preciso mencionar que gran parte de estos narradores que extrae sus escenarios de las zonas marginales ha eludido caer en la trampa de un soporte ideológico excesivamente obvio, trampa en la que sí resultaron apresados muchos de los realistas de los treinta [se refiere al grupo Amauta, al que pertenecieron Vallejo (El tungsteno, 1931) Y J. C. Mariátegui]. Quizá se mantiene la tendencia documentalista, quizá se observa el apego a la dura realidad; pero, en cualquier caso, no es frecuente el tono pretenciosamente revolucionario que echó a perder buena proporción del realismo indigenista".

Como vemos, estos nuevos prosadores de la ciudad, para lectores ciudadanos, han superado ya el marco del interior, de la aldea indígena como tópico y asunto literario exclusivo (no quiere decir que lo rechacen "a limine": pensemos en La casa 
verde, de Vargas Llosa; y en el reconocido valor de un Alegría o un Arguedas, por otro lado); están más allá del indigęismo idealizante, del mensaje social "dirigido" y sin matices, de los esquemas maniqueos y simplistas (tanto literarios, como sociales, económicos, políticos, raciales o de cualquier otro orden). Veamos al respecto, las manifestaciones de Vargas Llosa, en un artículo sobre J. M. Arguedas ("JMA descubre al indio auténtico", Visión del Perú. № 1 Lima, agosto 1964, pág. 4): "...el Perú no es "español" ni "indio", sino esas dos cosas y, además, otras. Existe también la comunidad "mestiza" y pequeños grupos demográficos dotados de personalidad propia: negros, chinos, indígenas selváticos. El proceso de integración de las dos unidades demográficas principales, la blanca y la india, es muy lento, pues ambas comunidades se mantienen separadas por una estructura económica que, desde la colonia, impide al indio incorporarse a la vida oficial y concentra todos los privilegios - el dinero, la tierra, el poder político- en manos de una casta, que a su vez constituye una ridícula minoría dentro de la minoría blanca. La integración sólo comenzará a ser efectiva cuando aquella estructura sea reemplazada por otra, que destruya las barreras económicas que hoy separan a blancos, indios y mestizos y ofrezca a todos las mismas posibilidades. Pero atengámonos a la situación actual del Perú. La integración no se ha producido ni puede producirse dentro del sistema vigente. Por lo tanto, resulta una pretensión irreal querer fundar una literatura peruana, exclusivamente en función de una de las comunidades culturales, renegando de las otras, No sería menos iluso creer que puede surgir una "literatura proletaria" mientras la burguesía siga en el poder".

Como vemos, la expresión acuñada por M. Castro Arenas, "neo-realismo urbano", alude a la intención realista que tienen estos escritores, frente a la otra generación también realista, la del 30 , y al mismo tiempo, la palabra "urbano" se refiere al nuevo modo de presentar a la gran urbe limeña, que hemos caracterizado. ¿Qué otras implicaciones o notas diferenciales caracterizan a este grupo o generación literaria?

En primer lugar, como hemos visto, estos escritores saben bien a qué público se dirigen (el de la ciudad, generalmente de clase media, el que lee en un país con $60 \%$ de analfabetismo), y lo hacen con la manifiesta intención de presentarles un mundo coincidente con el aquí y el ahora que están viviendo esos lectores. Las narraciones se desarrollan en el momento actual ("En octubre no hay milagros", de Reynoso, comienza: 
“Lima, 196..."), y en un espacio perfectamente ubicado y reconocible (Vargas Llosa coloca mapas de los sitios donde se desarrollan sus dos novelas, al principio de cada una). El pasatismo, la evasión, el exotismo, quedan descartados. Las barriadas, los basurales, el olor a pescado podrido, todo está allí formando el marco que condiciona los modos de vida de los conglomerados humanos (lo que más les interesa recalcar). La realidad aparece reflejada en sus aspectos más negativos: un caos sin salidas, un ambiente corrupto. Estos escritores están todavía en el momento de la destrucción. Son muy significativas las expresiones con que se refieren a su ciudad: Reynoso: (En octubre...): "Lima, Babilonia de la porquería" (pág. 115); "la fría y nebulosa Lima" (pág. 36); Ribeyro: (Los geniecillos...): "ciudad de masturbadores..." (p. 141); "no hay imagen más perfecta de la sociedad que un barco. Un barco peruano es la imagen de nuestro país. Podrido hasta las bodegas".

¿Cuál es el mensaje social de estos escritores? Consiste en la mera mostración de la decadencia de su sociedad, que habla por sí misma de la necesidad de reformar, de revolucionar sus estructuras, pero no da salidas ni soluciones. Así los finales, sin excepción, son negativos como saldo: todos los personajes terminan adaptándose al sistema, o vencidos por él a través de algún accidente (la muerte, la enfermedad, el desalojo, etc.), que trasunta el profundo pesimismo de los autores. Es interesantedestacar cómo, aun cuando todos se proponen presentar un amplio fresco que abarque la integridad de las capas sociales, los autores de este grupo se identifican inconscientemente con las clases medias, y desde allí hacen la crítica de las clases opresoras. Los pobres que aparecen suelen hacerlo a través de la visión un poco mitificada de la pandilla de los bajos fondos. Solamente Congrains Martín se detiene en los cuadros proletarios desde dentro. Nadie como él ha reflejado el drama de las unidades vecinales, la monotonía de la vida de sus habitantes, el horror de los basurales y las cinturas miserables.

Otro rasgo común es la carencia de héroes del tipo romántico; o mejor, podríamos decir que sí hay héroes, pero ellos son los seres comunes, anónimos, en su tremenda pugna con la sociedad de la cual son víctimas. El héroe individual queda diluido dentro de los grupos masivos, cuyos integrantes están entre sí aislados, incomunicados. Esta incomunicación y la pasividad de estos seres pueden resultar más enervantes para el lector (al modo kafkiano), que las grandes rebeliones en 
grupos organizados, que veíamos en "El tungsteno", por ejemplo, o que aparecen en Ciro Alegría, pero nunca en estos escritores.

Consecuentemente con esta posición destructora, los escritores neo-realistas presentan una actitud demitificadora, destructora de todas las convenciones y valores anteriores y tradicionales: la Patria, la Iglesia, la Historia, la Moral, el Orden, el Ejército; entidades que se escribían con mayúscula van a ser ahora cuestionadas, negadas, atacadas. Los escritores se constituyen entonces en generación parricida; adscriben con mayor simpatía a aquellos sectores que están en situación de minusvalía, entre ellos los adolescentes. De ahí la juventud de los protagonistas de sus narraciones, la presencia constante de pandillas o "colleras", su agrupación natural, regida por jeyes tan despiadadas y selváticas como las que rigen el mundo de los mayores. Los adolescentes están en la edad en que empiezan a sentir sin concesiones la coerción de la sociedad, sin tener a mano recursos para superarla; los reclamos del sexo, sin la libertad, la posibilidad ni el reconocimiento social necesarios para satisfacerlos plenamente (por eso la frecuencia con que aparece la masturbación, como necesidad y como rebelión). Las figuras de los mayores que aparecen son seres o bien débiles, fracasados, o bien repugnantes, monstruos sagrados que detentan el poder, la riqueza, que se entregan al libertinaje. ¡Y qué divorcio profundo entre ambas generaciones! Veamos un ejemplo de este divorcio en un momento de "La ciudad y los perros" que presenta claramente la oposición entre la realidad que afrontan los alumnos del Colegio, y los principios que les inculcaron sus padres: "el capellán del Colegio es un cura rubio y jovial que pronuncia sermones patrióticos donde cuenta la vida intachable de los próceres, su amor a Dios y al Perú y exalta la disciplina y el orden y compara a los militares con los misioneros, a los héroes con los mártires, a la Iglesia con el Ejército. Los cadetes estiman al capellán porque piensan que es un hombre de verdad: lo han visto, muchas veces, vestido de civil, merodeando por los bajos fondos del Callao, con aliento a alcohol y ojos viciosos". La propuesta es: antimilitarismo, anticlericalismo, revisionismo histórico y total.

En su actitud demitificadora, estos autores presentan el verdadero rostro de la adolescencia; raspan el barniz de oro y rosa con que tradicionalmente se lo cubría. Dos epígrafes son significativos de este hecho, que evidencian todas las obras: el de Paul Nizan, al comienzo de La ciudad y los perros: " $\mathrm{J}$ ' 
avait vingt ans. Je ne laisserai personne dire que c'est la plus bel age de la vie"; y el de Jean Genet, en la obra de Reynoso Los inocentes; relatos de collera: "Yo tenía 16 años... en el corazón, pero no tenia ni un solo lugar donde colocar el sentimiento de mi inocencia".

Otra característica de estos escritores es el sentirse a sí mismos como marginados. No encuentran estímulos en el medio; sólo desprecio, indiferencia. Nadie ha hecho manifiesta esta situación tantas veces como Vargas Llosa. De ahí su ida a Europa, su residencia desde hace 8 años en erste continente. En sus manifestaciones a la prensa, Vargas Llosa ha declarado repetidas veces su descontento por la situación del escritor en su país. En un reportaje que le hizo Emir Rodríguez Monegal (publicado en "Ercilla" Santiago, 6-7-1966), dijo: “... en el Perú, a diferencia de otros países, la literatura no interesa mucho a la gente, no repercute mucho"; más adelante manifestó: "lo que más le debo a Europa, lo que más he aprendido aquí, es a disciplinarme. He aprendido a trabajar, a escribir de una manera sistemática, concentrada, como trabaja un minero de La Oroya, así, con horario incluso, y he aprendido a enclaustrarme... En América Latina la literatura no ha sido tomada en serio. No la ha tomado en serio la sociedad, en primer lugar, y por consecuencia tampoco la ha tomado en serio el escritor. El escritor latinoamericano no asume su vocación de manera exclusiva, que es la única manera como se puede asumir, yo creo, la literatura. Como tma actividad, además, excluyente. Muchas veces se la toma como un pasatiempo, como una actividad paralela, como un hobby de domingo".

En otro reportaje anterior, realizado por Ismael Pinto, y publicado en el diario "Expreso", de Lima, (del 10-6-1966), expresó otros conceptos que completan este panorama: "IP¿Por qué crees que los escritores peruanos emigran, especialmente a París? En tu caso, ¿cuál fue el motivo? MVLL-En el Perú la literatura es una vocación desamparada. En nuestra sociedad, la mayoría no lee, y la minoría... muy poco. Los escritores están, prácticamente, segregados; la literatura no da de comer, a diferencia de lo que ocurre en otros lugares. Un escritor que es honesto, ¿qué hará para vivir? A veces desempeñar varios oficios, o uno, que lo aparta de su vocación. Tendrá qu hacer literatura domingos y feriados; la vocación muere o se frustra. Esto incita a partir a otro medio más rico, culturalmente; con mayores estímulos; y Europa los tiene. En mi caso, la necesidad material... y la tentación cultu- 
ral. IP- $\dot{C}$ Crees que, para triunfar, un escritor debe haber residido necesariamente en Europa? MVLL-No, absolutamente. Creo que el triunfo del escritor es realizarse a sí mismo como tal; el lugar no cuenta. Indice de triunfo no es vender un libro; sino el dar vida a sus "fantasmas"; sólo eso podrá satisfacerlo si es un verdadero escritor."

En cuanto a técnicas literarias, este grupo de escritores revela, en general, la tendencia hacia la renovación de estructuras (notamos sobre todo la influencia de Faulkner y Dos Passos), la dislocación del tiempo, el uso de la alusión indirecta o sugerente, la desaparición progresiva del narrador omnisciente, tras de las "cosas" (como señala Estuardo Núñez; de ahi su expresión "objetivismo"), el empleo creciente del monólogo interior.

Pasemos ahora a considerar la obra de Mario Vargas Llosa, cuya producción abarca fundametalmente la narrativa (novela y cuento) y el periodismo.

Su obra de ficción se inicia, según declaraciones del autor, con las poesías y relatos de su adolescencia, las cuales no han sido publicadas. En 1952 estrenó en Piura un drama: La huida. Entre los 16 y los 18 años escribe una serie de cuentos que aparecerán publicados en 1958 en Barcelona, bajo el título de Los jefes, libro reeditado el año pasado en Buenos Aires, por Jorge Alvarez. Otros cuentos publicados por Vargas Llosa son: La ciudad y el forastero (que forma parte de su última novela, "La casa verde", y apareció en Casa de Las Américas $\mathrm{N}^{\circ}$ 26; La Habana, oct.-nov. 1964); La casa verde (también de la novela homónima, Rev. Peruana de Cultura $\mathrm{N}^{\circ} 4$. Lima, enero de 1965); El abuelo (en "Crónicas bastante extrañas", J. Alvarez. Bs. As., 1965); Pichula Cuéllar (en Sur No 300. Bs. As., mayo-junio 1966); Día domingo (en "Lima en 10 cuentos". Lima, Biblioteca universitaria, 1966).

Su primera novela, La ciudad y los perros, la editó Seix Barral (premio Biblioteca Breve), en 1963. Apenas acabada esta obra, comienza su 2a. novela, La casa verde, publicada este año, también por Seix Barral (de ella, como ya dijimos, habían sido publicadas dos partes, los cuentos ya citados). Nuestro autor lleva ya, según ha declarado, un año de trabajo en su tercera novela, "sobre un guardaespaldas de la época de Odría, época de una dictadura mediocre, a la peruana", Vargas Llosa ha pasado, como vemos, del cuento a la novela. Cuando Ismael Pinto (en un reportaje publicado en "Expre- 
so", Lima, 10-6-66) le preguntó el por qué de este cambio, su respuesta fue la siguiente: "...yo creo que todos mis cuentos, empezando por Los jefes, son tentativas frustradas de novela. Ello no quiere decir que considere al cuento género menor; ni tampoco lo he desechado. En el Perú y en América, quizá se escriba más cuentos por la facilidad de publicarlos en revistas, diarios, etc. Y, también, porque significa menos disciplina que en la novela." En la misma entrevista, más adelante, Pinto le pregunta: "En tus novelas o cuentos, ¿qué influencias encuentras de autores peruanos o extranjeros? A lo que VLL responde "-No sé. En realidad, a veces los que más nos gustan son los que menos influyen. En mi caso, le debo mucho a Sartre. Lo empecé a leer en Media, y... a veces no lo entendía. Luego a Flaubert por su rigor; a Faulkner. Pero, a quien releo es a "Tirante el Blanco", un libro de caballerías, y quisiera poder escribir un día así; construir un mundo fabuloso con lo vivido y lo fantástico; hacerlo una totalidad".

Como periodista, su producción es múltiple. Ha escrito en "Casa de Las Américas", en "Expreso", de Lima, en "Revista Peruana de Cultura", en "Visión del Perú", en "Marcha", "Primera Plana", etc, generalmente sobre temas de crítiça literaria, o sobre temas de literatura en general, o sobre pintura. Ha sido reporteado varias veces, y también ha realizado él reportajes (recordemos el de Carpentier, en "Tiempos modernos", a Cortázar, cene"Expreso", a Buñuel, en "Primera plana", etc.

Una mirada de conjunto sobre sus obras de ficción, descubre que además de los rasgos ya indicados para su generación: realismo en la presentación descarnada de los estratos sociales, del verdadero rostro del país, rebeliones inútiles, angustia, pesimismo, incomunicación, intento demitificador, presencia de pandillas, la obra de Vargas Llosa presenta otras constantes bien netas: así por ejemplo el clima de violencia, el machismo dominante, la presencia avasalladora del sexo y de todo lo erótico, y otra muy importante sobre la que nos detendremos: el determinismo ambiental. ¿En qué consiste este determinismo? En la afirmación de imposibilidad del hombre de superar los condicionamientos del medio social y geográfico en que está inmerso; en un materialismo basado en el reconocimiento de la existencia de una realidad ajena al hombre, que le impone sus propias pautas, opuestas a los intereses, proyectos y fantasías individuales. El hombre reconoce que su destino no depende solamente de sus propias fuerzas; queda 
descartada la utopía del libre albedrío, la posición del héroe romántico, culminando por el contrario el anonadamiento de los personajes bajo una máquina social monstruosa, kafkiana, cuyos resortes de manejo se le escapan, y cuyos fines se desconocen o, simplemente, no existen.

La novela latinoamericana ya no es la "novela de la tierra" (como Zum Felde, entre otros, la definieron); ahora el hombre depende en ella de un complejo mucho más aplastante: de lo que pareciera ser la confabulación del medio social y el geográfico en su contra.

¿A qué se debe esta posición negativista, determinista del destino humano? A que Vargas Llosa, a mi entender, no ve salidas a la situación peruana y latinoamericana (al menos por ahora); pareciera no adherir plenamente a ninguno de los sistemas ideológicos que se le presentan; parece no tener una conciencia clara y definida de las situaciones, y por tanto tampoco la reflejan sus personajes. Pero ¿no se contradice esto con sus declaraciones, en las que se autodefine socialista? En su artículo sobre la condena a los escritores rusos Siniavsky y Daniel (publicado en. "Marcha", de Montevideo, el 4-4-66, y en "Expreso" de Lima, un mes más tarde, comienza diciendo: "Los escritores que creemos en el socialismo y que nos consideramos amigos de la URSS debemos ser los primeros en protestar por el enjuiciamiento...". Más adelante continúa: "Al pan pan y abvino vínoca el socialismo decide suprimir para siempre esa facultad humana que es la creación artística y eliminar de una vez por todas a ese espécimen social que se llama el escritor, o admite la literatura en su seno y, en ese caso, no tiene más remedio que aceptar un perpetuo torrente de ironías, sátiras y críticas...porque no hay creación artística sin inconformismo y rebelión...El escritor ha sido, es y seguirá siendo un descontento. Nadie que esté satisfecho es capaz de escribir dramas, cuentos o novelas que merezcan este nombre, nadie que esté de acuerdo con la realidad en la que vive acometería esa empresa tan desatinada y ambiciosa que es la invención de realidades verbales....la literatura es una forma de insurrección permanente". Vemos que toda la literatura de Vargas Llosa es típica (como la de los demás peruanos del grupo) de hombres disconformes, que elevan su disconformidad a la categoría de canon universal. A nosotros también puede parecernos esta manifestación de valor universal; pero, chasta dónde no está condicionada por nuestra propia situación, por la de toda Hispanoamérica y sus conflictos? ¿Es lícito pensarla como válida para toda la li- 
teratura, o podemos entender que haya escritores conformes con su tiempo, como algunos clásicos y algunos escritores socialistas, por ejemplo? Hay en Vargas Llosa una honda contradicción entre su postura pesimista y sus manifestaciones de adhesión al socialismo, que debe conllevar una visión optimista del futuro, la posesión de una clara perspectiva y un soporte ideológico neto y definido, que falta en Vargas Llosa. Nadie como Lukács ha señalado esta serie de contradicciones en los escritores que, como VLL, adscriben a lo que él (Lukács) llama realismo crítico, es decir, la posición de aquellos escritores que viven como burgueses, en una sociedad burguesa, y tienden ideológicamente hacia el socialismo. ¿Qué pasa entonces? El escritor critica su sociedad, pero como lo hace inevitablemente desde dentro de ella, no puede evadirse de sus propios condicionamientos. En "Significación actual del realismo crítico". Lukács dice: (pág. 114) "La afirmación del socialismo en el realismo crítico tendrá que seguir siendo siempre abstracta; aun cuando se intente concretar el problema, éste necesariamente sucederá desde fuera y no descle dentro".

El resultado de esta oposición es entonces una tensión, una lucha en la que, como no se vislumbran salidas, se continúa girando sobre sí mismo, sin ofrecer soluciones. Del dinamismo se pasa así a la estaticidad, y los dos polos de la literatura burguesa de que habla Lukács: vanguardismo y realismo crítico, se tocan.

Ahora bien, "el hecho de que VLL confene la realidad que presenta, sin ofrecer soluciones, no desmerece a mi entender en absoluto el valor de su obra. El escritor no está obligado a dar soluciones; basta con que el mundo que refleja trasunte una capacidad de visión crítica de la realidad, y esté configurado de una forma estéticamente valiosa. El escritor socialista, en cambio, subordina lo esencialmente literario a su misión política y social. En cierto sentido, se contradice como escritor. Pero esta no es la posición de VLL, quien en un reportaje aparecido en "Tiempos Modernos", dijo: "No soy partidario de la literatura militante. Cuando la novela se convierte en informe de defensa pierde su carácter novelístico porque persigue un objetivo limitado, inmediato. Reemplaza al periodismo, al panfleto, al ensayo; se pone en un plano que no le pertenece. La novela ciertamente influencia a la sociedad, cambia las conciencias, pero lentamente. Si el escritor se embarca en una literatura militante, pierde su libertad creadora, y para el artista ello es grave. Creo por el contrario en 
la literatura comprometida. Siendo latinoamericano creo en ello más que nadie; nosotros no debemos eludir la realidad, más aún, si lo quisiéramos no podríamos hacerlo, pues nos sale al encuentro".

En otro artículo, sobre Reynoso, Vargas Llosa dice: "El novelista es como el justo juez, como Dios, como la ley: no se casa con nadie."

Estas importantes manifestaciones nos llevan del plano ético al estético. Cosecuentemente con lo declarado, MVLL nunca subordina la calidad literaria a la intencionalidad ética o social. Es un cuidadoso artífice de la forma, y un permanente buscador de nuevas modalidades expresivas. En este sentido, toda esta nueva generación de autores peruanos tiene el gran mérito de defender y usar el lenguaje típicamente peruano, de la calle, en su forma oral, contra el tradicional casticismo y retoricismo que durante siglos agobió a la literatura de este país.

Analicemos ahora, breyemente, las dos novelas de Vargas Llosa, tratando de descubrir cómo se da en ellas el intento de renovación de las estructuras narrativas, plano en que este autor supera ampliamente a los demás de su generación.

\section{ESTRUCTURA Y TECNICA EN "LA CIUDAD Y LOS PERROS"}

Recordemos brevemente el argumento...Los protagonistas intentan destruir un orden, pero fatalmente terminan sometiéndose a él, reproduciendo los mismos errores que intentaron combatir.

La estructura de la novela es cerrada: consta de dos partes de extensión pareja, subdividida cada una en ocho especies de capítulos, que a su vez se subdividen en escenas; y un epílogo, de tres escenas, donde se narra el destino final de otros tantos personajes: Gamboa, Alberto y Jaguar.

Dentro de esta trama cerrada, no hay un desarrollo único, lineal. Percibimos la influencia del lenguaje cinematográfico (cada vez más dislocado), en la variedad y alternancia de los enfoques, cada uno de los cuales corresponde a un personaje central, un estilo, un lenguaje y un "tempo" propios, formando su entrelazamiento una trama compleja como la sociedad estratificada que representa. El ritmo es movido, los desplazamientos son frecuentes. Las distintas escenas, que 
alternan entre sí, siguen los hilos de diversas historias que podrían formar aisladamente otras tantas novelas; la del Jaguar, de Alberto, del Esclavo, de Gamboa, del Colegio Leoncio Prado.

El ojo de la cámara del narrador se sitúa en 4 planos distintos, que parecen adentrarse cada vez más en los personajes, y corresponden a otras tantas técnicas y niveles de lenguaje: 1) el ojo inmóvil; 2) el ojo móvil; 3) el monólogo tradicional; 4) el monólogo interior.

El primer plano, que llamamos ojo inmóvil, supone un hablante que narra en 3a. persona, y está situado a una distancia tal de los personajes que le permite ser imparcial y abarcar el cuadro de conjunto. Presenta a los cadetes y oficiales en la acción y en el diálogo; describe los ambientes y las costumbres. Podemos ejemplificar esta forma narrativa citando el comienzo de la 2a. parte (pág. 35): "Cuando el viento de la madrugada irrumpe sobre La Perla, empujando la neblina hacia el mar y disolviéndola, y el recinto del Colegio Militar Leoncio Prado se aclara como una habitación colmada de humo cuyas ventanas acaban de abrirse, un soldado anónimo aparece bostezando en el umbral del galpón y avanza restregándose los ojos hacia las cuadras..." El narrador, como vemos, se coloca a cierta distancia, presenta el ambiente en forma aparentemente impersonal y objetiva, casi fotográfica (o mejor, fílmica), apero recuperando para el lector el oculto sentido poético de la realidad más común. En el $2^{\circ}$ plano: el ojo móvil, el rarrador usa también la 3a. persona, pero disminuye su alejamiento, abandona un poco su imparcialidad para acercar el foco de su cámara a determinado personaje, que asume entonces el rol protagónico. La cámara sigue a este personaje en sus movimientos, diálogos, reflexiones, sensaciones; se identifica con su particular perspectiva y se limita a ella, ganando en penetración humana lo que pierde en ubicuidad. El personaje más seguido por la cámara es Alberto (notemos que es también el que tiene mayor status y movilidad social, el que más se ha identificado, entre otras razones, por sus trabajos literarios, con Vargas Llosa). Veamos una de las cscenas donde el ojo móvil de la cámara se ha centrado sobre este personaje: "Se abre la puerta del baño. Alberto ve la cara pálida del Esclavo: las literas lo degüellan a medida que avanza. Está peinado y afeitado. "Se levanta antes de la diana para llegar primero a la fila", piensa Alberto. Cierra los ojos. Siente que el Esclavo se detiene junto a su cama y le toca el hombro. Entreabre los ojos: la cabeza del 
Esclavo culmina un cuerpo esquelético, devorado por el pi. jama azul." (aquí destaco la perspectiva intencionalmente limitada del narrador, y el valor de las figuras que emplea).

La 3a. técnica es la del monólogo tradicional. La representan los monólogos del Jaguar, que son 12, y están en su mayoría dentro de la 2a. parte. El Jaguar asume la primera persona, pero sus parlamentos presuponen la presencia de un interlocutor o público que lo escucha contar sus recuerdos. A través de estos monólogos el Jaguar va contando la historia de su niñez, todo el período anterior a su ingreso al Leoncio Prado.

La 4a. modalidad narrativa es la de los monólogos interiores (13 en total), cuya figura central es la del Boa. El estilo varía profundamente. El lenguaje se hace íntimo, suelto, popular, se libera de las trabas racionales o de las deformaciones que la presencia de los demás impone al lenguaje, tal como surge espontáneamente en un nivel pre-hablado. Abunda en incoherencias; el ritmo es atropellado. Veamos un ejemplo (pág. 66): "Quieta, perra, saca tus malditos dientes, Malpapeadita. Estaba lleno de gente, los soldados habían traído sillas del comedor o eso fue otra vez, pero digamos que estaba lleno de gente, imposible distinguir al general Mendoza entre tanto uniforme. El que tiene más medallas y me voy a quedar seco de risa si me acuerdo del micro,el colmo de la mala suerte, cómo ños divertimos, me voy a hacer pis de risa, me corte la cabeza que si está Gamboa, voy a reventar de tanta risa si me acuerdo delcuinicto."' Notemos que habla, aparentemente, con la perra (desdoblamiento de sí mismo-soledad).

¿Qué se propone Vargas Llosa con esta dialéctica entre las formas narrativas nuevas y las tradicionales, con esta variedad de enfoques? Se propone dar una visión lo más rica y variada posible de la realidad, presentar el mayor número de ángulos posibles, de manera de dar margen a la creación y el juicio del lector; para él, en eso consiste el realismo literario.

Pasemos ahora a analizar brevemente la 2a. novela de Vargas Llosa: La casa verde. Aquí la técnica se complica, el intento de renovación estructural se agiganta. Cinco son las historias que se entremezclan como una maraña (historias basadas en hechos y escenarios reales). Las dos primeras tienen lugar en Piura, pequeña ciudad al N. O. del Perú, donde vivió Vargas Llosa un tiempo de chico. Las dos historias piuranas 
son: la de Anselmo (el arpista ciego, fundador de la casa verde), y la de la Mangachería, "barrio de vagabundos, mendigos y artistas"; de alli se destacan los Inconquistables: José, el Mono, Josefino y Lituma, asiduos concurrentes de la casa verde.

Las otras tres historias tienen lugar en la selva amazónica del N. E. peruano, donde viven las tribus de los aguarunas y los huambisas, que impresionaron fuertemente al autor, cuando visitó esas regiones, porque "viven en la Edad de Piedra." En la confluencia de los ríos Nieva y Marañón hay una factoría de caucheros y una misión de religiosas españolas: el Convento de Santa María de Nieva. Allí es recogida Bonifacia, otro de los personajes principales, cuya parábola selva-Misión-servicio doméstico-prostíbulo, habla por sí misma de la necesidad de poner fin a la injusticia con los indios, de la ambigüedad del mito del progreso y la evangelización, y su complicidad frecuente con la explotación y con el engaño.

La cuarta historia es la de Jum, cacique del pueblo urakusa, acerca del cual nos dice MVLL en su ya cit. Diálogo con E. R. Monegal: "que fue castigado y torturado por haber vretendido vender el caucho directamente en Iquitos, y sin pasar por los intermediarios que los explotan. Le rompieron la frente de un golpe de linterna...después lo azotaron y lo colgaron de dos árboles...Le cortaron el pelo, que es una ofensa terrible para los indios. Yo hablé con los torturadores cuando estuve, hace poco, y me encontré con que eran gente muy simple y amable, cque nocparecíanoentender lo que habían hecho. Los soldados cayeron sobre el pueblo, agarraron a Jum, violaron a las indias delante de sus maridos y se llevaron al cacique. Así aprenderían a no rebelarse contra los intermediarios. Lo peor es que ya el propio Jum habia aceptado el castigo y se había convertido en el ser más sumiso y servil. Los intermediarios eran también unos pobres hombres, al nivel de las larvas." Notemos en estas manifestaciones una de las carcterísticas que más admiro en MVLL: la objetividad de sus juicios, esa característica que él quiere para todos los narradores, cuando dice: "el novelista es como el justo juez: como Dios, como la ley: no se casa con nadie." De esta manera la crítica revierte sobre el sistema, no sobre los hombres, que de una u otra manera son sus víctimas (aun los explotadores).

La 5a. historia es la de Fushia, el japonés explotador, ambicioso y desalmado, de quien la selva se venga transformán- 
dolo en una sola llaga putrefacta. Este episodio es uno de los más trágicos del libro (junto con el de Toñita), que no escatima la pintura cruda y despiadada de las situaciones.

Alrededor de cstos personajes centrales giran otros: Aquilino, Lalita, Adrián Nieves, etc. Directa o tangencialmente, todos ellos (los personajes principales y los secundarios), se vinculan o desembocan en la Casa Verde, especie de centro neurálgico de la obra. ¿Qué es esta Casa Verde que da nombre al libro, y en la cual parecen resumirse todos los destinos? Es un prostíbulo, surgido como una excrecencia en las afueras de la tranquila ciudad de Piura, y que desde el otro lado del puente ejerce su influjo inquietante, su maléfico magnetismo. En un momento dado, el lector descubre que hay dos casas verdes, sucesivas en el tiempo. Parece que la primera fue quemada por los indignados habitantes "honestos" de Piura, reproduciendo la búsqueda de purificación por el fuego de Sodoma y Gomorra. Pero la casa renació de sus cenizas, demostrando que es necesario reemplazar los viejos esquemas maniqueos, buscar un nuevo lenguaje, nuevos valores, porque el hombre está hecho de bien y mal, de mentira y verdad, de razón y sinrazón.

Puede ocurrir también que una sola sea la casa verde real y la otra se difumine en la penumbra incierta del mito, o que ninguna de las dos exista. Las alusiones son intencionalmente veladas y evasivas. Vargas Llosa no nos da nunca certezas absolutas; nos deja en la duda, nos da margen para que nos construyamos aun epoco cadal iunonde nosotros nuestra propia novela, sobre la base de su propuesta.

Junto al vívido cuadro regionalista (sentimos, respiramos la sequedad del arenal piurano y la humedad pegajosa, fecunda y erótica de la selva), además del juego continuo con el espacio y el tiempo quebrados, yuxtapuestos, dislocados, simultáneos, lo que más se destaca en esta extensa novela (tiene 430 páginas), es la multiplicidad de niveles que el autor baraja con suma maestría, la riqueza de planos que se juegan sucesiva o simultáneamente en la obra: Veamos cuáles son esos planos, algunos de los cuales han sido señalados acertadamente por el crítico Oviedo, y que constituyen otras tantas vías de acceso a la obra posibles: 1) el simbólico-crítico: detrás y a través de la ficción, el autor representa y denuncia la realidad total que es el Perú. No es de ninguna manera gratuito ni accidental que esta novela-mundo lleve el nombre de un prostíbulo. Vargas Llosa ama a su país, y por lo 
mismo le duelen su estratificación, su injusticia social, su corrupción institucionalizada. Por eso busca, a través de la Iiteratura de testimonio y denuncia, conmover al lector, hacerlo consciente y responsable de lo que es su realidad, sacarlo de su aceptación pasiva y abúlica. 2) el mítico, que se trasunta por ejemplo en toda la historia de la fundación misteriosa del prostíbulo, y las consecuentes habladurías de la gente. La incertidumbre entre lo mítico y lo real nos descoloca, nos desconcierta, que es precisamente lo que se propone el autor. 3) lo exótico: todo el ambiente de la selva, los indios, configuran una instancia real, pero extraña para nosotros; nos lleva al conocimiento de esferas hasta ahora desconocidas al lector peruano, y que sin embargo son tan peruanas como la realidad limeña que lo circunda. 4) lo heroico, apenas esbozado, por ejemplo, en la sublevación de Jum y la aventura de Fushía. Pero notemos enseguida lo que ya adelantamos para esta generación de escritores: la heroicidad no se da al modo romántico: uno termina sometido, el otro pobre, abandonado y leproso.

La prosa se flexibiliza asimismo en los más variados enfoques $\mathrm{y}$ estilos, desde la narración objetiva e impersonal a la pura subjetividad de los breves pero numerosos monólogos interiores, a los diálogos vivaces, con cuyo montaje a veces se logra descubrir perspectivas insospechadas para la literatura; desde la palabra-ruido hasta la palabra-sentimiento y la palabra-instinto, que trasuntám una cuidadosa elaboración, una aguda preocupación por el estilo. La persona narradora pasa sin solución de continuidadede la primera a la tercera, y como lo ha destacado el ya citado crítico Oviedo, hay hasta un hermoso y muy difícil uso de la segunda persona, en el trozo cuya cita transcribo: "Ahora sí, atrévete, anda a su banco todas las mañanas, toca sus cabellos, cómprale fruta, llévala a La Estrella del Norte, pasea con ella bajo el sol ardiente, quiérela tanto como en esos días." El personaje que parece desdoblarse y hablarse a sí mismo es Anselmo. O también podría ser el narrador quien se dirige al mismo Anselmo.

Es imposible agotar aquí, por razones de tiempo, el análisis apenas esbozado de esta novela tan rica, cuya complejidad a menudo desconcierta al lector, lo hace sentirse perdido entre sus callejuelas entrecruzadas. Pero una lectura atenta y compenetrada recompensa ampliamente al lector, con el regalo de un deslumbramiento nuevo, de la percepción de mundos extraños, exóticos, desgarrantes, insospechados. Bás- 
tenos decir que obras como La casa verde y La ciudad y los perros, junto con otras de la talla de Rayuela, Los premios, La región más transparente, Los albañiles, Sobre héroes y tumbas, Pedro Páramo, La muerte de Artemio Cruz, etc., de alguna manera nos reivindican, nos llenan de orgullo a la vez que nos hacen sentir en toda su intensidad el dolor de Suramérica; nos reconcilian con esa tarea "de loco", arrebatadora, desgarradora y angustiante, que es la creación literaria.

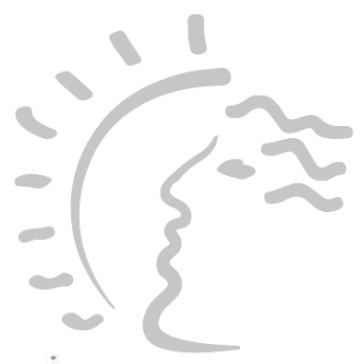

Biblioteca de Letras

"Jorge Puccinelli Converso» 